\title{
Co (II) and Zn (II) Metal Complexes of Heterocyclic Schiff Bases: A Synthesis, Spectral and Antimicrobial Study
}

\author{
SACHIN R. JOSHI ${ }^{1}$ and SEEMA I. HABIB ${ }^{2}$ \\ 'Department of Chemistry, Shankarrao Chavan Mahavidyalaya, Ardhapur, India. \\ ${ }^{2}$ Department of Chemistry, NSB College. Nanded (M.S.), India. \\ *Corresponding author E-mail: seemahabib12@gmail.com
} http://dx.doi.org/10.13005/ojc/300353

(Received: May 29, 2014; Accepted: July 01, 2014)

\begin{abstract}
The Schiff bases have been synthesised by the reaction of Benzoinoxime primary ligand with heterocyclic compounds such as 2-aminothiazole $\left(\mathrm{SL}_{1}\right)$ and 8-hydroxyquinoline $\left(\mathrm{SL}_{2}\right)$ to form the secondary ligand, which than react with the metal halides to form complexes of Co (II) and Zn (II). The elemental analysis data shows that the metal to ligand ratio in all Co (II) simple is 1:2 for simple complexes and 1:2:2 for metal complex with oxime as a primary ligand and $\mathrm{SL}_{1}$ as a secondary ligand while it is 1:2:1 for metal complex with oxime as a primary ligand and $\mathrm{SL}_{3}$ as a secondary ligand whereas Zn (II) complexes of mixed ligand exhibit the stoichiometry 1:2:2. The structural features have been determined from IR, UV-Vis, and XRD data. All the complex shows a distorted octahedral geometry to mononuclear Co (II) complexes of mixed ligands, while square planner geometry to mononuclear Co (II) complexes of oximes. Zn (II) complexes of mixed ligands shows a distorted octahedral geometry, while square planner geometry to mononuclear Zn (II) complexes of oximes. All the synthesised compounds were screened for antimicrobial activity.
\end{abstract}

Key words: Schiff base, Antimicrobial activity, heterocyclic compounds.

\section{INTRODUCTION}

Metal complexes of Schiff bases are extensively studied due to synthetic flexibility, selectivity and sensitivity towards a variety of metal atoms ${ }^{1}$. Schiff bases are most widely used as chelating ligands in coordination chemistry². They are also useful in catalysis and in medicine as antibiotics, antiallergic and antitumor agents ${ }^{3}$.
The metal complexes of Schiff bases derived from heterocyclic compounds have been the centre of attraction for many workers in recent years ${ }^{4-8}$. A study through the literature revealed that no work has been realized on the preparation and characterization of metal complexes of mixed heterocyclic Schiff bases derived by the reaction of $\mathrm{Co}$ (II) and Ni (II) Benzoinoxime primary ligand with heterocyclic compounds such as 2-aminothiazole and 8-hydroxyquinoline to form the secondary 
ligand, an attempt has been made to synthesize and characterize some novel metal complexes of these Schiff base ligands. The prepared ligands as well as their metal complexes were also investigated for their in vitro activity against some bacterial and fungal species. The purpose of the work was to understand the coordination as well as the biological chemistry of these novel synthesized compounds.

\section{MATERIAL AND METHOD}

\section{Synthesis of Benzoinoxime}

Benzoinoxime was prepared by standard procedure $^{9}$ in which $10 \mathrm{gm}(0.047 \mathrm{~mol})$ of benzoin and $20 \mathrm{gm}(25 \mathrm{ml})$ of rectified spirit together with an aqueous solution of $8.0 \mathrm{gm}(0.087 \mathrm{~mol})$ of hydroxylamine was taken together in a $250 \mathrm{ml}$ round bottom flask. Before using hydroxylamine hydrochloride was neutralized with $4.4 \mathrm{gm}$ (0.091 mol) of sodium hydroxide. The mixture was refluxed for $60 \mathrm{~min}$. Then water was added to precipitate benzoinoxime. It was cooled in ice bath. The solid was filtered with solution at pump and it was washed with water finally the product was recrystallised by using ethanol.

The purity of the product was checked by TLC and Melting point. Melting point of Benzoin Oxime is $151^{\circ} \mathrm{C}$.
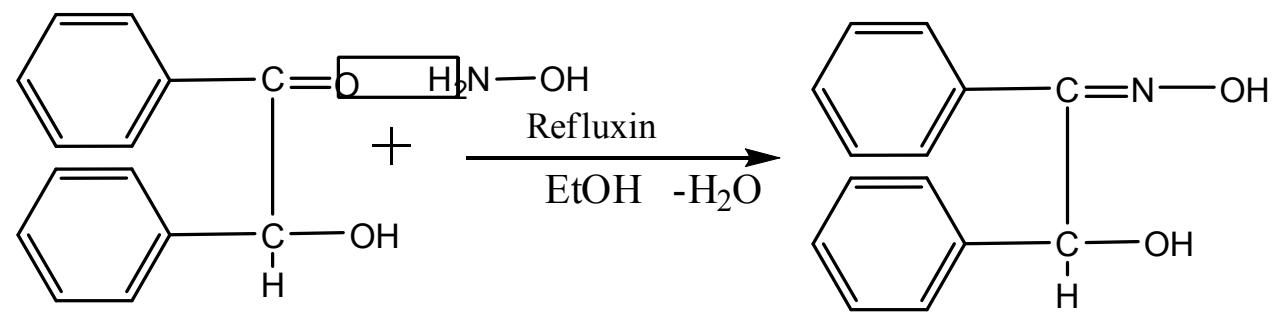

\section{Scheme}

Preparation of simple complexes of Benzoinoxime The following complexes of $\mathrm{CO}$ Benzoinoxime and $\mathrm{Zn}$ - Benzoinoxime have been synthesized as follows ${ }^{10-14}$.

The above metal complexes were prepared by mixing the solution of the primary ligand $\left[\left(\mathrm{PL}_{2}\right.\right.$ Benzoinoxime) ( 0.06 mole)] in $80 \mathrm{ml}$ of boiling ethanol with 0.03 mole of metal(II) chloride solution in $20 \mathrm{ml}$ of distilled water. The mixture was magnetically stirred for about one hour. Then coloured precipitate (except Zn) were formed which was filtered out and washed with hot water or methanol then dried over vacuum. The purity was checked by using TLC.

Preparation of mixed ligand complexes of Co (II), Zn (II) Benzoinoxime with S- $\mathrm{L}_{1}$ and $S-\mathrm{L}_{3}$

Co (II), Zn (II) Benzoinoxime complex solution $(0.01 \mathrm{~mol})$ in ethanol and solution of $\mathrm{S}-\mathrm{L}_{1}$ and $\mathrm{S}-\mathrm{L}_{3}$ were dissolved in $25 \mathrm{ml}$ ethanol or $25 \mathrm{ml} \mathrm{CH}_{2} \mathrm{Cl}_{2}$ were mixed separately in $250 \mathrm{ml}$ round bottom flask. The reaction mixture was refluxed on a water bath for 2-4 hrs on cooling the coloured precipitate separate that was filtered, washed with cold hexane solvent and dried under vacuum over night.

\section{RESULTS AND DISCUSSION}

\section{Elemental analysis and magnetic moment}

Elemental analysis data reveals that the observed values of percentage of $\mathrm{C}, \mathrm{H}, \mathrm{N}$, halogen and metal ion are in good agreement with values predicted and calculated for $\mathrm{Co}(\mathrm{II})$ complexes with $1: 2$ metal to ligand ratio for simple complexes and 1:2:2 for metal complex with oxime as a primary ligand and $\mathrm{SL}_{1}$ as a secondary ligand while it is $1: 2: 1$ for metal complex with oxime as a primary ligand and $\mathrm{SL}_{3}$ as a secondary ligand. The elemental analysis indicates that $\mathrm{Zn}(\mathrm{II})$ complexes of mixed ligand exhibit the stoichiometry 1:2:2. The Zn (II) complexes undergo decomposition at high temperature.

The magnetic moment values are in the range of 2.74 to 3.25 B.M. of mixed ligand complexes 


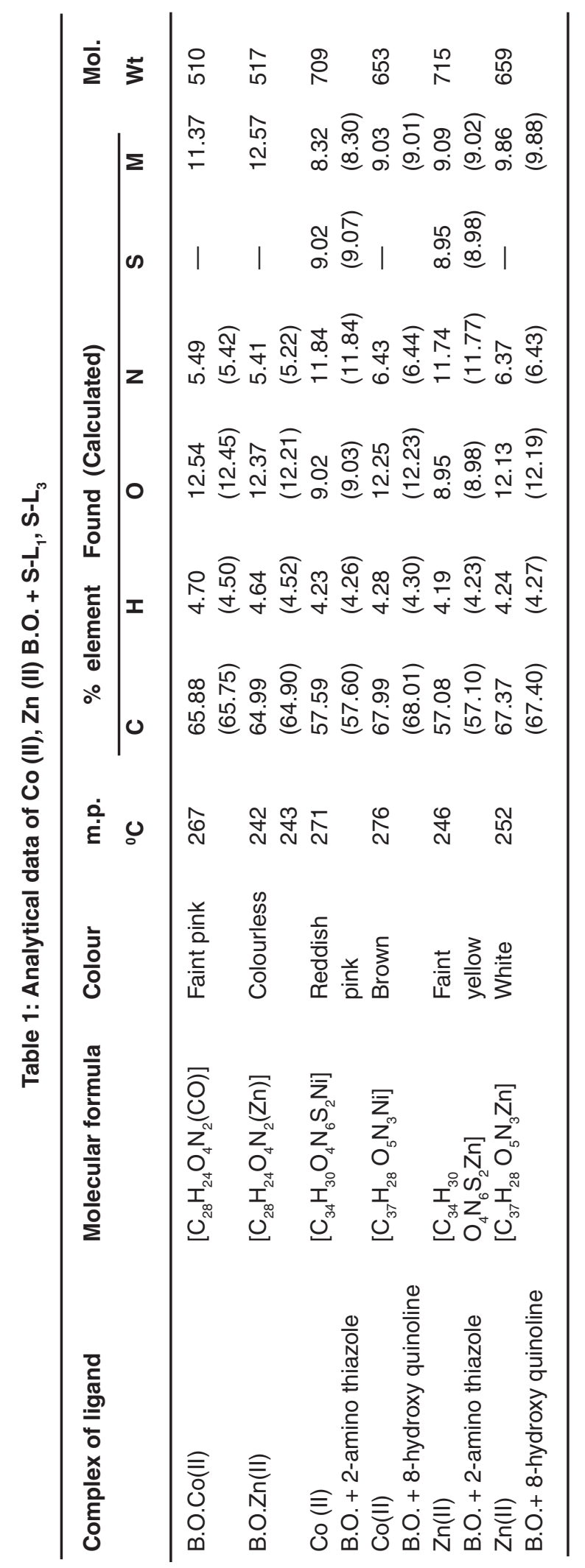


in present work indicates octahedral geometry ${ }^{15}$. Due to completely filled'd' shell as expected for $\mathrm{Zn}(\mathrm{II})$ ion it exhibits diamagnetic nature. The present complexes are found to be diamagnetic in nature for the square plannear ${ }^{16}$ geometry.

The electronic spectra of Co (II) complexes exhibit absorption bands at $10661-10870 \mathrm{~cm}^{-1}\left(\mathrm{D}_{1}\right)$, $16694-18149 \mathrm{~cm}^{-1}\left(D_{2}\right)$ and 20661-25189 $\left(D_{3}\right)$ from lower energy level to higher energy level, which also clearly indicate the square planer and octahedral stereochemistry of Co (II) complexes ${ }^{15}$.

The ligand field parameter values i.e. LFSE observed in the range 30.383 to $30.979 \mathrm{Kcal} /$ mole for mixed ligand complexes and 42.986 to
$43.445 \mathrm{kcal} / \mathrm{mole}$ for simple complexes are in good agreement with octahedral CO (II) complexes and square planner complexes respectively. In present work the electronic absorption spectrum of Zn (II) complexes shows only one absorption band in UVvisible spectrum in the range $357 \mathrm{~nm}\left(2800 \mathrm{~cm}^{-1}\right)$ to $372 \mathrm{~nm}\left(26882 \mathrm{~cm}^{-1}\right)$. This is due to absence of $d$ - $d$ transition. This observed peak is because of metal to ligand charge transfer spectra. The values are in agreement with octahedral geometry of these complexes $^{17,18,19}$.

\section{IR Spectroscopy}

The azomethine $\mathrm{C}=\mathrm{N}$ stretching is found at $1650 \mathrm{~cm}^{-1}$ for benzoinoxime ${ }^{20}$. For Co(II) and

Table 2: Selected IR bands (cm-1) of Co (II) and Zn (II) BO with $\mathrm{SL}_{1}, \mathrm{SL}_{3}$ (mixed ligand) complexes

\begin{tabular}{llllllllc}
\hline Complex & $\mathbf{C}=\mathbf{N}$ & $\mathbf{C}=\mathbf{C}$ & $\begin{array}{l}\text { Aromatic } \\
\mathbf{C}-\mathbf{O}\end{array}$ & $\begin{array}{l}\text { Oximino } \\
\text { O-H }\end{array}$ & $\begin{array}{l}\text { M-N } \\
\text { Prim. } \\
\text { Lig. }\end{array}$ & $\begin{array}{l}\text { M-O } \\
\text { Prim. } \\
\text { Lig. }\end{array}$ & $\begin{array}{l}\text { M-O / M-N } \\
\text { Sec. Lig. }\end{array}$ & $\begin{array}{c}-\mathbf{N H} \\
\text { Sec. } \\
\text { Lig. }\end{array}$ \\
\hline $\mathrm{Co}(\mathrm{BO})+\mathrm{SL}_{1} 1579$ & $1416-1600$ & 1084 & 3312 & 494 & 509 & $/ 426$ & 3450 \\
$\mathrm{Co}(\mathrm{BO})+\mathrm{SL}_{3} 1578$ & $1414-1610$ & 1090 & 3308 & 491 & 508 & $430 /$ & -- \\
$\mathrm{Zn}(\mathrm{BO})+\mathrm{SL}_{1} 1578$ & $1425-1600$ & 1106 & 3367 & 484 & 544 & $/ 428$ & 3452 \\
$\mathrm{Zn}(\mathrm{BO})+\mathrm{SL}_{3} 1571$ & $1422-1600$ & 1109 & 3369 & 487 & 547 & $429 /$ & -- \\
\hline
\end{tabular}

Table 3: Antimcrobial Activity

\begin{tabular}{llcccc}
\hline S. & Ligand / Complex & \multicolumn{2}{c}{ Bacterial Strain } & \multicolumn{2}{c}{ Fungal Strain } \\
No. & & E. coli & S.aureus & A. niger & A. flavus \\
\hline 1 & & 8 & 9 & 8 & 9 \\
2 & $\mathrm{PL}_{2}$ & 5 & 0 & 0 & 6 \\
3 & $\mathrm{SL}_{1}$ & 0 & 12 & 0 & 0 \\
4 & $\mathrm{Co}(\mathrm{II}) \mathrm{PL2}$ & 0 & 0 & 0 & 0 \\
5 & $\mathrm{Co}(\mathrm{II}) \mathrm{PL2}+\mathrm{SL1}$ & 0 & 0 & 2 & 6 \\
6 & $\mathrm{Co}(\mathrm{II}) \mathrm{PL2}+\mathrm{SL3}$ & 0 & 14 & 0 & 0 \\
7 & $\mathrm{Zn}(\mathrm{II}) \mathrm{PL2}$ & 0 & 0 & 0 & 0 \\
8 & Zn(II) PL2 + SL1 & 0 & 0 & 3 & 5 \\
9 & Zn(II) PL2 + SL3 & 0 & 9 & 0 & 0 \\
\hline
\end{tabular}

$\mathrm{Zn}(\mathrm{II})$ Benzoinoxime the same band shifted to lower frequency and appears at $1623 \mathrm{~cm}^{-1}, 1647 \mathrm{~cm}^{-1}$, for their adducts it is again to lower frequency and appear in the range of $1576-1580 \mathrm{~cm}^{-1}$ and 1571 $1578 \mathrm{~cm}^{-1}$. This indicates that the azomethine group of the ligand is coordinated to metal ion via nitrogen atom $^{21}$
The ligand benzoinoxime exhibit four peaks in the range of $1430 \mathrm{~cm}^{-1}$ to $1575 \mathrm{~cm}^{-1}$ attributed to aromatic $\mathrm{C}=\mathrm{C}$ stretch for two aromatic ring while its $\mathrm{Co}(\mathrm{II})$ and $\mathrm{Zn}$ (II) complexes exhibits the same stretch at $1415-1600 \mathrm{~cm}^{-1}$ and at $1446-1601 \mathrm{~cm}-1$ and the mixed ligand complexes exhibit it in the range of $1414-1600 \mathrm{~cm}^{-1}, 1418-1600 \mathrm{~cm}^{-1}$. 
In the case of mixed ligand complex of 2-aminothiazole and 8-hydroxyquinoline frequency of $\mathrm{OH}$ is shifted to $3389-3398 \mathrm{~cm}^{-1}$ showing weakening of intramolecular hydrogen bonding.

The ligand band at $1403 \mathrm{~cm}^{-1}$ is due to the $\mathrm{O}-\mathrm{H}$ deformation mode of the oximino hydroxyl group it identified at 1640-1645 $\mathrm{cm}^{-1}$ for Co(II) and $\mathrm{Zn}(\mathrm{II})$ adducts ( mixed ligand complexes) indicating that the oximino hydroxyl group remains intact ${ }^{22}$ in the complex of $\mathrm{Co}$ (II) with all heterocylic ligands used in present work. However the $\mathrm{O}-\mathrm{H}$ deformation band of the phenolic oxygen appears at the $1315 \mathrm{~cm}^{-1}$ in the ligands disappears in the complexes showing co-ordination through phenolic oxygen.

Co (II), Zn (II) of Benzoine oxime complexes shows at $486 \mathrm{~cm}^{-1}$ due to metal-nitrogen stretching and at $492 \mathrm{~cm}^{-1}, 539 \mathrm{~cm}^{-1}$ due to metal-oxygen stretching. The metal oxygen bond shifted to higher value in case of mixed ligand complex of $\mathrm{Co}(\mathrm{II})$, $\mathrm{Zn}$ (II) of Benzoineoxime and appears in the range $504-511 \mathrm{~cm}^{-1}, 544-547 \mathrm{~cm}^{-1}$.

A metal nitrogen weak band appears for all mixed ligand complexes in the range $491-495 \mathrm{~cm}^{-1}$ this is due to formation of a bond between nitrogen atom of secondary ligand and central metal cobalt ion. In case of mixed ligand complex of Co (II), Zn (II) Benzoineoxime and 8-hydroxyquinoline one more band is observed at $430 \mathrm{~cm}^{-1}, 429 \mathrm{~cm}^{-1}$. This clearly indicates that the phenolic oxygen bonded to Co (II).

In mixed ligand complexes of 2-aminothiazole and 2-aminopyridine the bands appears at $3450 \mathrm{~cm}^{-1}$ and $3248 \mathrm{~cm}^{-1}$. This is due to free $\mathrm{N}-\mathrm{H}$ - stretch proves that the $-\mathrm{NH}_{2}$ group do not participate in complex formation.

\section{X-ray Diffraction Study of Co (II) Complexes}

The X-ray power diffractogram of [Co(II) $\left(\mathrm{PL}_{1}+\left(\mathrm{SL}_{3}\right)\right]$ complex was selected for the study and is reported in (Fig.5.74). The XRD data was fed to computer to get the values of $h, k, l, d$, for various refluxes using $1 / \mathrm{d}^{2}$ values. The indexing of data with respect to prominent peaks was done independently by trial and error method. The standard deviation in crystal parameter found is within permissible limit. The observed density of $\left[\mathrm{Co}(\mathrm{II})\left(\mathrm{PL}_{1}+\left(\mathrm{SL}_{3}\right)\right]\right.$ is 1.1234 and calculated density is 1.4220 . The porosity percentage was calculated from the observed and calculated density which is found to be $21.004 \%$. The crystallographic data of the complexes fit perfectly in monoclinic crystal system with four molecules per unit cell. The probable spaces group is $\mathrm{P}^{2} / \mathrm{m}$.

\section{Antimicrobial activity}

\section{Antibacterial activity by ditch-plate method}

Nutrient agar of $20 \mathrm{ml}$. was placed in a flat bottomed Petri dish. When solidified, $4 \mathrm{ml}$ of second nutrient sol., Seed with test bacteria was poured evenly onto the first layer (at $48^{\circ} \mathrm{C}$ ). As soon as the second layer was solidified, in six sterile stainless steel cylinders were added an equal amount of a standard penicillin solution of concentrations 2.0, $1.5,1.0,0.5$ and $0.25 \mathrm{mg} / \mathrm{ml}$. Sample of the test solutions were deposited analogously on the other Petri dishes. The dishes were incubated at $37^{\circ} \mathrm{C}$ for 16-18 hours. During this time the penicillin diffuses out of the cylinder into the surrounding agar and suppresses the growth of the test organism. Thus the cylinder was surrounded by clear zone, free of bacteria. The diameter of each zone provides an index of activity of the penicillin preparation. The mean values obtained from 10-20 standard plates are used to draw a curve and the biological activity of the test solution in international unit is determined using conversion table.

\section{Antifungal activity by paper disc diffusion method}

Whatman No. 1 filter paper disc of $5 \mathrm{~mm}$ diameter were sterilized by autoclaving for $15 \mathrm{~min}$. at $121^{\circ} \mathrm{C}$. The sterile disks were impregnated with different compounds. Agar plates were surface inoculated uniformly from the both culture of the tested microorganisms. The impregnated disks were placed on the medium suitably spaced apart and plates were incubated at $28^{\circ} \mathrm{C}$ for 72 hours. The inhibition zones caused by various compounds on the microorganisms were examined.

\section{CONCLUSION}

All the Co(II) complexes are pinkish, brown coloured, whereas $\mathrm{Zn}$ (II) complexes are faint yellow, lemon yellow and white in colour, stable to air and moisture but decompose at high temperature 
rather than showing sharp melting points. They are insoluble in water and soluble in DMSO, DMF and dioxane. In the present investigation, on the basis of elemental analysis, magnetic moment, electronic absorption spectral data, LFSE values shows a distorted octahedral geometry to mononuclear Co(II) complexes of mixed ligands, while square planner geometry to mononuclear $\mathrm{Co}$ (II) complexes of oximes. The higher LFSE values of Co(II) complexes shows that these complexes are less stabilized than $\mathrm{Cu}(\mathrm{II})$ and $\mathrm{Ni}(\mathrm{II})$ complexes of oximes and heterocyclic ligands.
In the present investigation, on the basis of elemental analysis, magnetic moment, electronic absorption spectral data, shows a distorted octahedral geometry to mononuclear Zn(II) complexes of mixed ligands, while square planner geometry to mononuclear Zn(II) complexes of oximes

\section{ACKNOWLEDGEMENTS}

The authors are thankful to the principal NSB College Nanded for providing laboratory facilities. The authors are also thankful to the Head IICT Hyderabad, for providing spectral data.

\section{REFERENCES}

1. Spinu, C.; and Kriza A.; Acta Chim. Slov. 2000, 47, 179.

2. Shibuya, Y.; Nabari, K.; Kondo, M.; Yasue, S.; Maeeda, K.; Uchida, F.; Kawaguchi, H.; Chem. Lett. 2008, 37 , 78.

3. Gangani, B. J.; Parsania, P. H.; Spectrosc. Lett. 2007, 40, 97.

4. Sindhukumari, B.; Rijuulal, G.; Mohanan, K.; Synth. React. Inorg. Met.-Org. Nano-Met. Chem. 2009, 39, 24.

5. Thankamony, M.; Mohanan, K.; Indian J. Chem. 2007, 46A, 247.

6. Raman, N.; Dhaveethu Raju, J.; Sakthivel, A.; J. Chem. Sci. 2007,119, 303.

7. Wang, D.; Yang, Y.; Yang, Y.; Zhao, T.; Wu, X.; Wang, S.; Hou,Y.; Chen, W.; Chin. Sci. Bull. 2006, 51, 785.

8. Shivakumar, K.; Shashidhar, M. B.; Halli.; Russ. J. Phys. Chem. 2008, 82, 2269.

9. Vogel's Text book of practical organic chemistry; P.885.

10. Attia, A.S.; El-Moushtly, S.F.; and El-shahat, M.F.; Synthesis and reactivity in Inog. \& metal organic chem. 2002, 32(3), 509-572.

11. Adkhis Benali-Baiticho, A.; Khan, M. A.; Bouet, G.; Synth.React.Inog.Met-Org.Chem. 2000, 30(10), 1849-1858.
12. Adkhis and etal., Synth.React.Inog.Met-Org. Chem. 2003, 33(1), 33-50.

13. Canpolat, E.; Kaya, M.; Turk J. of Chem. 2004, 28235-28242.

14. Chondhekar, T.K.; Ph.D. Thesis, Marathwada University, Aurangabad, 1979, 61, 126, P. 3238.

15. Krishna, P.G. \& Philips,G.H.; Ind. J. of Chem. 2008, 17A, 1962.

16. Henri, L.K.W.; Tagenine, J. and Gupta, B.M.; Indian J. of Chem. 2001, 40 A, 299.

17. Maurya, R.C.; Patel, P.; and Rajput, S.; Synthesis and Reactivity In Inog. \& Metal-Org. Chem. 2003, 33 (5), 809.

18. Shayma, A.; Shaker, E.J. of Chem. 2010, 7(4), 1600.

19. Prasad, R.L.; and Bala, R.; Synth. React. Inog. Met. Org. Chem. 1987, 17(7), 711.

20. Esmaiek Suleimani.; J. of Chem. Soc. Pak. 2009, 31 (3).

21. Das, D.C.; Panda, A.K.; Jena, P.; Patjoshi, S.B.; and Mahaptra, A.; J. of ind.Chem. Soc. 2002, 79 (1), 48-50.

22. Biradardar, N. S.; Patil, B.R.; and Kulkarni, B.H.; J. Inog. Nucl. Chem. 1975, 37, 901. 